\title{
Nm23-H1 Regulates Glucose-Stimulated Insulin Secretion in Pancreatic $\beta$-Cells via Arf6-Rac1 Signaling Axis
}

\author{
Rajakrishnan Veluthakala,b David Kaetzelc Anjaneyulu Kowlurua,b
}

\begin{abstract}
aBeta-cell Biochemistry Laboratory, John D. Dingell VA Medical Center and 'Department of Pharmaceutical Sciences, Wayne State University, Detroit, MI 48201, and 'Department of Biochemistry and Molecular Biology, University of Maryland School of Medicine, Baltimore, Maryland 21201
\end{abstract}

\section{Key Words}

nm23-H1 • Pancreatic $\beta$-cell • Insulin secretion • Rac1 and Arf6

\begin{abstract}
Background: A growing body of evidence implicates novel roles for nm23-like proteins in the regulation of cellular functions. However, roles of these proteins in islet function and glucose-stimulated insulin secretion (GSIS) remain largely unknown. Methods: siRNA-nm23$\mathrm{H} 1$ and nucleoside diphosphate kinase and histidine kinase-deficient mutants of nm23-H1 (K12Q and H118F) were used to assess roles of nm23-H1 in GSIS. Results: siRNA-mediated knockdown of the expression of nm23-H1 markedly inhibited GSIS in INS-1 832/13 cells. $\mathrm{Nm} 23-\mathrm{H} 1$ knockdown also resulted in significant inhibition of glucose-mediated activation of Arf6, a small G-protein, which has been implicated in GSIS. Expression of K12Q and H118F mutants of nm23-H1 in INS-1 832/13 cells led to inhibition of glucose-induced translocation and membrane association of Rac1, another small G-protein, which is downstream to Arf6 in the signaling events leading to GSIS. A significant inhibition of GSIS was also seen in these cells expressing K12Q and H118F. Conclusions: We conclude that the nm23-H1 activation step is upstream of Arf6 activation in signaling events leading to GSIS. NDP kinase and histidine kinase functions of $\mathrm{nm} 23-\mathrm{H} 1$ are necessary for glucose-induced membrane association of Rac1 and ensuing insulin secretion. We present the first evidence for regulation of GSIS by $\mathrm{nm} 23-\mathrm{H} 1$ in pancreatic $\beta$-cells.
\end{abstract}


Veluthakal/Kaetzel/Kowluru: $\mathrm{nm} 23-\mathrm{H} 1$ in Insulin Secretion

\section{Introduction}

It is well established that glucose-induced insulin secretion (GSIS) from pancreatic $\beta$ cells is mediated largely via the generation of soluble second messengers, such as cyclic nucleotides, hydrolytic products of phospholipases (A 2, C, and D), and adenine nucleotides [1]. However, the precise molecular and cellular mechanisms underlying GSIS remain only partially understood. After its entry into the $\beta$-cell, glucose is metabolized with a resultant increase in the intracellular ATP/ADP ratio. Such an increase in the ATP results in closure of ATP-sensitive $\mathrm{K}^{+}$channels localized on the plasma membrane as a consequence of which membrane depolarization occurs. This, in turn, promotes the influx of extracellular calcium through the voltage-sensitive calcium channels. Exposure of isolated $\beta$-cells to stimulatory glucose concentrations also results in mobilization of calcium from the calcium stores endogenous to the islet $\beta$-cell. The resultant net increase in intracellular calcium has been implicated in the transport of insulin-containing secretory granules to the plasma membrane for fusion and release of insulin into the circulation [2,3].

In addition to regulation of GSIS by the adenine nucleotides, several earlier studies have examined the contributory roles for guanine nucleotides (i.e., GTP) in physiological insulin secretion. For example, using selective inhibitors of the GTP biosynthetic pathway (e.g., mycophenolic acid), a permissive role for GTP in physiological insulin secretion was established [4,5]. Although the exact mechanisms underlying the regulatory role (s) of GTP remain elusive, accumulating evidence from multiple laboratories, including our own, indicates that intracellular GTP levels could partake in the activation of one (or more) Gproteins [6-8]. Using various biochemical, cell biological and pharmacological approaches, recent studies have identified several small G-proteins (e.g., Arf6, Cdc42 and Rac1) as regulators of GSIS $[1,9]$. Evidence from our laboratory also suggested a sequential activation of these G-proteins in the cascade of events leading to insulin release. For example, Arf6 is activated within $1 \mathrm{~min}$ of exposure of $\beta$-cells to glucose followed by activation of Cdc42 $(\sim 3$ $\min )$ and $\operatorname{Rac1}(\sim 15-20 \mathrm{~min})$ [10].

Nm23/NDPK-like enzymes catalyze the transfer of terminal phosphates from nucleoside triphosphates (e.g., ATP) to nucleoside diphosphates (e.g., GDP) to yield their respective nucleoside triphosphates (e.g., GTP) [11]. Emerging experimental evidence [1,11] indicates that, in addition to the generation of nucleoside triphosphates, nm23/NDPK plays key roles in the direct activation of certain G-proteins (e.g., trimeric as well as monomeric) as well as phosphorylation and/or regulation of several key enzymes of intermediary metabolism (e.g., ATP citrate lyase, aldolase, pyruvate kinase, glucose-6-phosphatase, and succinyl thiokinase). Although multiple regulatory roles have been suggested for NDPK, one of the unique roles of this enzyme is its ability to promote the synthesis of GTP and the subsequent activation of specific G-proteins. The latter is thought to occur via channeling of GTP to the "vicinity" of candidate G-proteins for their functional activation. NDPK also mediates transphosphorylation of GDP bound to G-proteins (inactive conformation) to their GTPbound (active conformation) of G-proteins [11-14].

Despite this compelling evidence to implicate novel regulatory roles of $\mathrm{nm} 23-\mathrm{H} 1$ in cell function, and high degree of expression of this protein in pancreatic $\beta$-cells, little is known about its regulatory role in islet $\beta$-cell function and insulin secretion, specifically at the level of G-protein activation. Therefore, we undertook the current investigation to determine the mechanisms regulating activation of specific G-proteins (Arf6 and Rac1), which we and others $[1,9,10,15-19]$ have shown to be involved in GSIS in pancreatic $\beta$-cells. We have utilized siRNA and histidine kinase and NDP kinase deficient mutants of nm23-H1 to address these questions. Our data provide the first evidence to suggest that GSIS involves activation of $\mathrm{nm} 23 \mathrm{H} 1 \rightarrow$ Arf6 $\rightarrow$ Rac1 signaling pathway. 


\section{Materials and Methods}

\section{Materials}

The rat insulin ELISA kit was purchased from American Laboratory Products Co (Windham, NH). Effectene and HiPerFect transfection reagent kits were purchased from Qiagen (Valencia, CA). Antiserum directed against nm23-H1 was from Santa Cruz Biotechnology (Santa Cruz, CA). Rac1 antiserum was from BD Biosciences (San Jose, CA). Rac1 and Arf6 activation assay kits were from Cytoskeleton Inc. (Denver, CO) and from PIERCE (Rockford, IL), respectively.

\section{Transfection of WT, K12Q and H118F mutants of nm23-H1 and quantitation of GSIS}

INS-1 832/13 cells [seeded at a density of $2.5 \times 10^{5}$ cells per well in a 24 well plate] were transfected using Effectene transfection kit, with a maximum of $0.2 \mu \mathrm{g}$ of either wild type (WT), K12Q or H118F mutants of nm23-H1 according to manufacturer's instructions. Six hours after transfection cells were cultured overnight in the presence of $5 \mathrm{mM}$ glucose and $2.5 \%$ fetal bovine serum. After pre-incubation in the presence of $3 \mathrm{mM}$ glucose for another $1 \mathrm{~h}$, cells were incubated in the presence of low (5mM) or high (20mM) glucose, for $45 \mathrm{~min}$ at $37^{\circ} \mathrm{C}$. The supernatant was then removed, centrifuged at $300 \mathrm{~g}$ for $10 \mathrm{~min}$, and the amount of insulin released was quantitated by ELISA as we described previously in $[17,18]$.

SiRNA mediated knockdown of nm23-H1

Endogenous expression of nm23-H1 was depleted by transfecting INS-1 832/13 cells with siRNA, a 21-oligonucleotide RNA forming a 19-base pair duplex core. INS-1 832/13 cells were plated on 24-well plates, and transfection with nm23-H1-siRNA was performed at 50-60\% confluence at a final concentration of $100 \mathrm{nmol} / \mathrm{l}$ using HiPerFect transfection reagent. To assess specificity of siRNA, cells were transfected in parallel (as above) with non-targeting siRNA that included at least four nucleotide mismatches with all known mouse, rat, and human gene (i.e., scrambled siRNA) duplexes and the efficiency of nm23-H1 knockdown was determined by Western blot analysis. For, GSIS studies post transfected cells were cultured overnight in the presence of $5 \mathrm{mM}$ glucose and $2.5 \%$ fetal bovine serum. After pre-incubation in the presence of $3 \mathrm{mM}$ glucose for another $1 \mathrm{~h}$, cells were incubated in the presence of low $(5 \mathrm{mM})$ or high (20mM) glucose, for $45 \mathrm{~min}$ at $37^{\circ} \mathrm{C}$. The supernatant was then removed, centrifuged at $300 \mathrm{~g}$ for $10 \mathrm{~min}$, and the amount of insulin released was quantitated by ELISA as we described previously $[17,18]$.

\section{Quantitation of Arf6-GTP in pancreatic $\beta$-cells}

Active Arf6 (Arf6.GTP) was quantitated by a pull-down assay as we described previously [10]. Briefly, INS-1 832/13 cells deficient in nm23-H1 (by RNAi method) were incubated either with low (5mM) or high $(20 \mathrm{mM})$ glucose, after the incubation period, the medium was aspirated and cells were washed with ice-cold PBS. Cells were lysed with $500 \mu \mathrm{l}$ of lysis buffer and the lysates were clarified by centrifugation at $16,000 \mathrm{~g}$ at $4^{\circ} \mathrm{C}$ for $15 \mathrm{~min}$ and incubated $400 \mu \mathrm{g}$ of protein with $100 \mu \mathrm{l}$ of glutathione resin and $100 \mu \mathrm{g}$ of GST-GGA3-PBD beads at $4^{\circ} \mathrm{C}$ for $1 \mathrm{~h}$ with gentle rocking, following which the reaction mixture was spun at $6000 \mathrm{~g}$ for $30 \mathrm{~s}$. The GST-tagged beads were washed and proteins were separated by SDS-PAGE and activated Arf6 was identified by Western blotting.

\section{Translocation and membrane association of Rac1}

The degree of translocation of cytosolic Rac1 to the membrane fraction was assessed as we described previously $[17,18]$. In brief, INS-1 832/13 cells were transfected with WT, K12Q or H118F mutants of nm23$\mathrm{H} 1$ and were cultured overnight in low glucose-containing media. The next day, cells were further incubated in the presence of either low $(5 \mathrm{mM})$ or high $(20 \mathrm{mM})$ glucose for $30 \mathrm{~min}$ at $37^{\circ} \mathrm{C}$. After the incubation period, cells were homogenized by sonication and subjected to a single-step centrifugation at $105,000 \mathrm{~g}$ for $60 \mathrm{~min}$. Total membrane (pellet) and soluble (supernatant) fractions were separated and used for the determination of relative abundance of Rac1 in these fractions by Western blotting.

Other assays and statistical analysis of experimental data

Protein concentration in cell lysates was quantitated according to Bradford using BSA as a standard. The statistical significance of the differences between the experimental conditions was determined by Student's t-test. A $p$ value $<0.05$ was considered significant. 


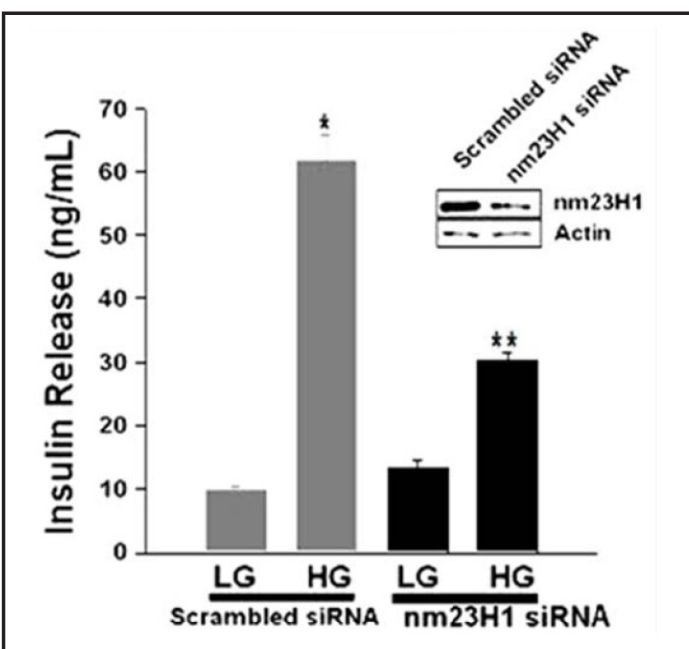

Fig. 1. siRNA-mediated knockdown of nm23-H1 inhibits glucose-stimulated insulin secretion in INS-1 $832 / 13$ cells. GSIS was quantitated in INS-1 832/13 cells transfected with either scrambled or nm23siRNA. A Western blot indicating the knockdown of $\mathrm{nm} 23-\mathrm{H} 1$ was provided in the inset. Data are mean \pm SEM from 3 determinations in each case. ${ }^{*} \mathrm{p}<0.05$ vs LG $[5 \mathrm{mM}]$, and ${ }^{* *}$ vs. HG $[20 \mathrm{mM}]$ in cells transfected with scrambled siRNA.

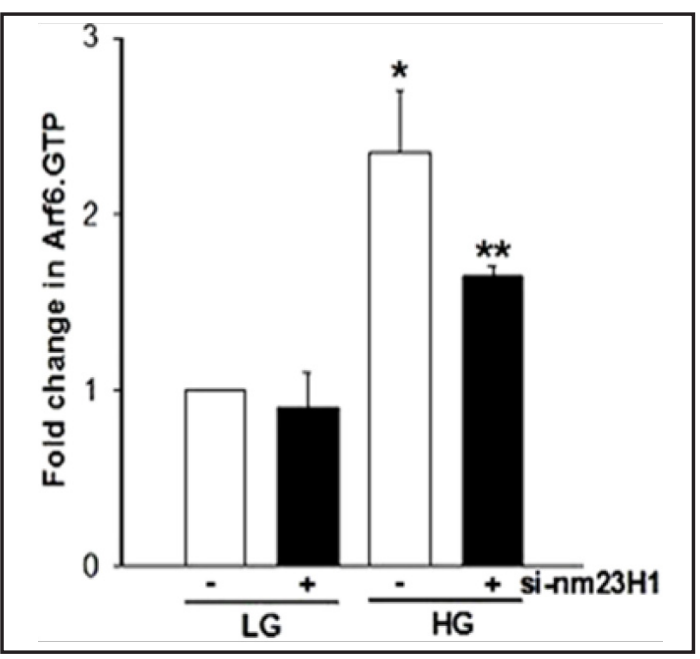

Fig. 2. siRNA-mediated knockdown of nm23-H1 markedly inhibits the ability of glucose to activate Arf6 in INS-1 832/13 cells. Glucose-induced Arf6 activation was quantitated in INS-1 832/13 cells transfected with either scrambled [-] or siRNA-nm23-H1 [+] as shown [see Methods for additional details]. Data are mean \pm SEM from 3 determinations. * $\mathrm{p}<0.05$ vs LG $[5 \mathrm{mM}]$, and ${ }^{* *}$ vs. HG $[20 \mathrm{mM}]$ in cells transfected with scrambled siRNA.

\section{Results}

Depletion of nm23-H1 by RNAi significantly attenuated GSIS in INS-1 832/13 cells

Earlier studies from this laboratory have identified at least three forms of nm23 in pancreatic $\beta$-cells. These include $\mathrm{nm} 23-\mathrm{H} 1, \mathrm{~nm} 23-\mathrm{H} 2$ and nm23-H4 [20]. We demonstrated that $\mathrm{nm} 23-\mathrm{H} 1$ was predominantly cytosolic and $\mathrm{nm} 23-\mathrm{H} 2$ was both membranous and cytosolic in distribution. We observed that nm23-H4 was exclusively localized in the mitochondrial fraction [20]. One of the objectives of this study is to investigate contributory roles of nm23-H1 in GSIS, specifically at the level of G-protein function. To address this, at the outset, we knocked down the endogenous expression of nm23-H1 in INS-1 832/13 cells using siRNA-nm23-H1. Data depicted in Figure 1 (inset) suggest greater than $50 \%$ reduction in the expression of nm23-H1 following transfection of siRNA-nm23-H1. Data shown in Figure 1 also demonstrate that stimulatory concentrations of glucose augmented ( $\sim 6$ fold) insulin secretion in cells transfected with scrambled siRNA (bar 1 vs. 2 ). We noticed $\sim 50$ $\%$ inhibition in GSIS in cells in which endogenous expression of nm23-H1 was knocked down using siRNA-nm23-H1 (bar 2 vs. 4). Together, these findings demonstrate a critical regulatory role for $\mathrm{nm} 23-\mathrm{H} 1$ in the signaling events leading to GSIS.

Depletion of nm23-H1 by RNAi significantly reduced glucose-induced activation of Arf6 in INS-1_832/13 $\beta$-cells

Recent investigations from our laboratory and others have implicated regulatory roles for small G-proteins (e.g., Arf6, Cdc42 and Rac1) in GSIS [1, 9, 10, 16-19, 21-24]. More importantly, time course experiments suggested that GSIS involves activation of Cdc42 ( $\sim 3$ min of exposure to glucose) followed by Rac1 ( $\sim 15-20$ min of exposure to glucose). Recent studies from our laboratory placed activation of Arf6 as an upstream signaling step to the activation of Cdc42Rac1 by glucose leading to insulin secretion [10]. Therefore, we investigated, herein, roles if any for $\mathrm{nm} 23-\mathrm{H} 1$ in the activation of small G-proteins, specifically Arf6 in INS-1 832/13 cells. To address this, glucose-induced Arf6 activation 


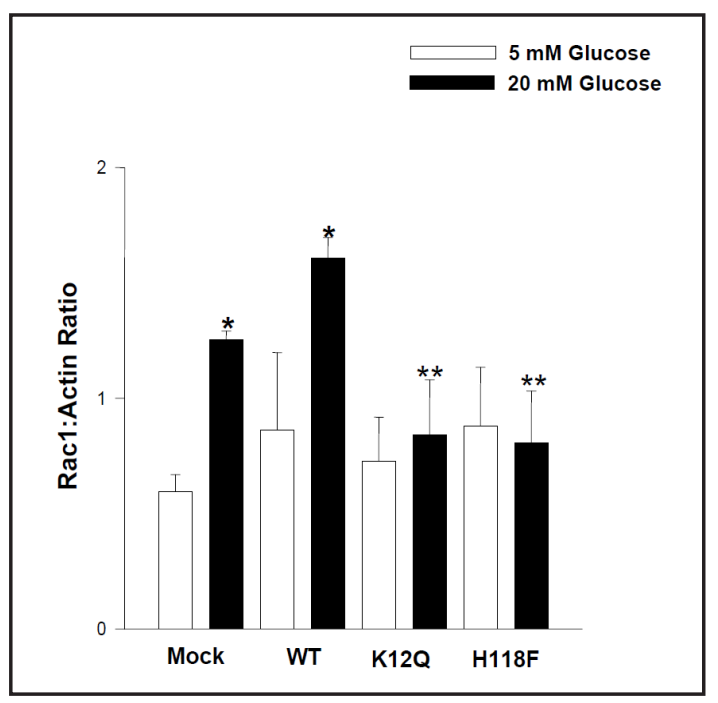

Fig. 3. Inactive mutants of $\mathrm{nm} 23-\mathrm{H} 1$ inhibit glucose-induced membrane association of Rac1 and insulin secretion in INS-1 832/13 cells. Glucoseinduced translocation and membrane association was measured in INS-1 832/13 cells transfected with either WT or inactive mutants of nm23-H1 as indicated. Data are expressed as Rac1:actin ratios, and are mean \pm SEM from 3 determinations. $*$ p $<0.05$ vs. $L G$, and ${ }^{* *}$ not significant vs. LG.

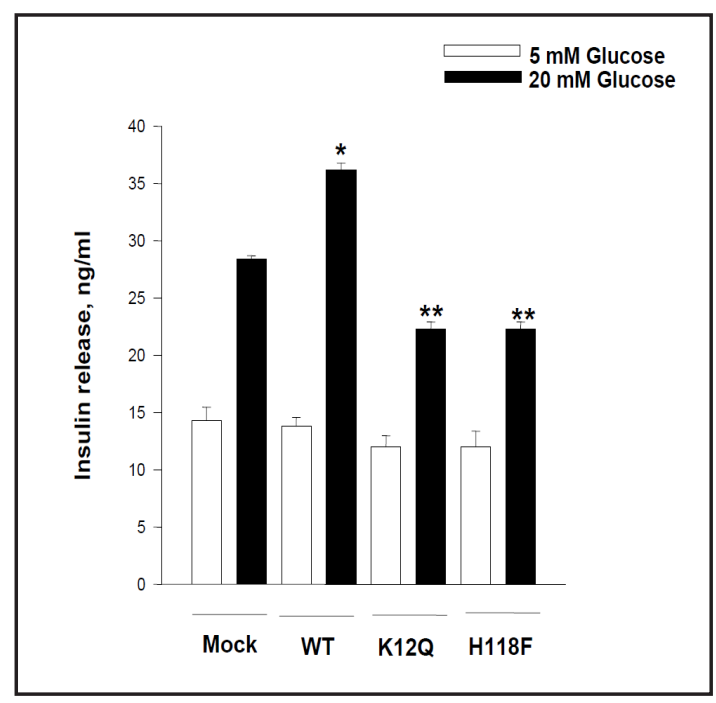

Fig. 4. Inactive mutants of nm23-H1 inhibit glucoseinduced membrane association of Rac1 and insulin secretion in INS-1 832/13 cells. GSIS was measured in INS-1 832/13 cells transfected with either WT or inactive mutants of nm23-H1 as indicated. Data are mean \pm SEM from 3 determinations. ${ }^{*} \mathrm{p}<0.05$ vs. LG under respective experimental conditions, and ** $\mathrm{p}<0.05$ vs. HG in mock or WT transfected cells.

was quantitated in cells in which nm23-H1 was knocked down using siRNA-nm23-H1 (as in Fig. 1). Data depicted in Figure 2 demonstrate a significant activation of Arf6, by glucose in cells expressing the scramble siRNA (bar 1 vs. bar 3). However, silencing of expression of nm23-H1 in these cells markedly reduced the ability of glucose to induce Arf6 activation suggesting that Arf6 activation is downstream to nm23-H1 activation in glucose-induced signaling events leading to insulin release.

Histidine kinase and NDP kinase deficient mutants of nm23-H1 significantly impair glucose-induced_membrane association of Rac1 and associated insulin secretion in INS-1 $832 / 13$ cells

Several earlier studies have demonstrated that nm23-H1 is endowed with several biological/enzymatic functions including the NDP kinase activity, histidine kinase activity and exonuclease activities [25-30]. The NDP kinase activity mediates the generation of nucleotide triphosphates from nucleotide diphosphosphate via transphosphorylation reactions $[25,29]$. The histidine kinase functions of nm23-H1 appear to be much more distinct since they regulate phosphorylation of histidine residues of cellular proteins, which is necessary for their functional regulation [26]. Lastly, the exonuclease functions of nm23$\mathrm{H} 1$ have been implicated in DNA repair mechanisms $[27,28]$. In the current study, we utilized nm23-H1 mutants without NDP kinase, histidine kinase and exonuclease activities (K12Q mutant) and without NDP kinase and histidine kinase activities, but with exonuclease activity (H118F mutant). We compared their biological effects against the WT protein expressing all the three activities. Herein, we first quantitated glucose-induced membrane association of Rac1 (a hallmark of its activation) in INS-1 832/13 cells expressing WT, K12Q or H118F mutants. Data in Figure 3 demonstrate a significant increase in glucose-induced membrane association of Rac1 in cells under mock transfection [bar 1 vs. 2] and in cell expressing the WT nm23-H1 [bar 3 vs.4]. However, glucose failed to enhance the translocation of Rac1 to the membrane in cells expressing K12Q (bar 4 vs.6) or H118F (bar 4 vs. 8) mutants of nm23- 
H1. These data indicate that both NDP kinase and histidine kinase, but not the exonuclease functions of nm23-H1 are necessary for glucose-induced translocation of Rac1.

In the last set of experiments, we quantitated GSIS in INS-1 832/13 cells expressing WT, K12Q or H118F mutants of nm23-H1 to further validate our hypothesis that glucoseinduced, nm23H1-mediated membrane association of Rac1 is necessary for GSIS to occur. Data described in Figure 4 demonstrate a significant increase in GSIS in mock transfected (bar 1 vs. 2) or WT nm23-H1 transfected (bar 3 vs. bar 4) INS-1 832/13 cells. However, we noticed a marked attenuation in GSIS in cells expressing the K12Q or H118F mutant of nm23H1 when compared to GSIS in mock or WT transfected cells. Together, data in Figure 3 and 4 validates the hypothesis that both NDP kinase and histidine kinase, but not exonuclease functions, are necessary for GSIS to occur.

\section{Discussion}

The overall objective of the current study is to assess potential regulatory roles for $\mathrm{nm} 23-\mathrm{H} 1$ in physiological insulin secretion, and to examine roles for this protein in the regulation of small G-protein (Rac1 and Arf6) functions in the islet $\beta$-cell, which is necessary for GSIS to occur. Nm23like enzymes are endowed with NDP Kinase, histidine kinase, and exonuclease functions [25-30]. Salient features of our study are: siRNA-mediated knockdown of the endogenous expression of nm23-H1 markedly attenuates GSIS in INS-1 832/13 cells; (ii) a significant reduction in glucose-induced Arf6 activation in nm23-H1 depleted cells; (iii) NDP kinase and histidine kinase-deficient mutants of nm23-H1 significantly reduced glucose-induced translocation of Rac1 to the membrane, and associated insulin secretion; and (iv) exonuclease function of nm23-H1 plays no role in aforementioned $\beta$-cell functions.

It is widely perceived that NDPK plays the role of a house-keeping enzyme in the maintenance of intracellular GTP [30]. Using various cellular, biochemical and physiological assays, we first reported regulatory roles for NDP kinase in clonal $\beta$-cells, normal rat islets and human islets [14]. Additional studies from our laboratory have demonstrated expression and subcellular distribution of $\mathrm{nm} 23-\mathrm{H} 1, \mathrm{~nm} 23-\mathrm{H} 2$ and $\mathrm{nm} 23-\mathrm{H} 4$ in pancreatic $\beta$-cells [20]. Our findings accrued in the current study clearly suggest novel roles for this protein in $\beta$-cell function, specifically at the level of G-protein activation and membrane association leading to insulin secretion.

Emerging evidence implicates nm23-like enzymes as regulators of cellular function, including G-protein activation, cell proliferation and apoptosis [11-14, 31]. As stated above, $\mathrm{nm} 23-\mathrm{H} 1$ is endowed with at least three key functions, namely NDP kinase, histidine kinase and exonuclease activities [25-30]. In the context of NDP kinase functions, several earlier studies have demonstrated that nm23-like enzymes facilitate intracellular generation of GTP via transphosphorylation of GDP in the presence of ATP. The resultant G-protein activation is felt to occur via channeling of GTP to the "vicinity" of candidate G-proteins for their functional activation [11-14]. Alternatively, nm23-like enzymes are also involved in the activation of Gproteins via transphosphorylation of GDP-bound to G-proteins to their GTP-bound active conformations [32]. Lastly, earlier studies have also demonstrated non-receptor-dependent activation of candidate G-proteins by novel histidine kinases. For example, studies from our laboratory and Wieland's laboratory have demonstrated transient phosphorylation of histidine residues on the $\beta$-subunit of heterotrimeric G-proteins by histidine kinases, and the phosphate on the histidine residue is then transferred to the GDP bound to the $\alpha$-subunit to result in G $\alpha$.GTP (functionally active confirmation) $[13,14]$. No definitive data are available yet to conclusively demonstrate the nm23-H1 like enzymes phosphorylate $\beta$-subunits of trimeric G-proteins by their endogenous histidine kinase activity. Despite such evidence in other cells types, and its abundant expression in the islet $\beta$-cell [20], the regulatory roles of $\mathrm{nm} 23-\mathrm{H} 1$ in GSIS remain poorly understood. Our current data clearly suggest that both NDP kinase and histidine kinase functions of nm23-H1 appear to be critical for glucose-induced translocation and membrane association of Rac1. 
One of the salient findings of our current investigation is that glucose-induced activation of Arf6 is under the control of nm23-H1. Lawrence and Birnbaum have recently demonstrated roles for Arf6, a small G-protein, in insulin secretion [19]. More recently, we reported that ARNO as GEF for Arf6 in pancreatic $\beta$-cells [10]. We reported that inactive mutants of Arf6 (Arf6-T27N), ARNO (ARNO-E156K), siRNA-Arf6 or siRNA-ARNO significantly attenuated GSIS in $\beta$-cells [10]. secinH3, a selective inhibitor of ARNO/Arf6 signaling axis, also inhibited GSIS in INS-1 832/13 cells and rat islets. Stimulatory concentrations of glucose promoted Arf6 activation, which was inhibited by secinH3 or siRNA-ARNO, suggesting that ARNO/ Arf6 signaling cascade is necessary for GSIS. SecinH3 or siRNA-ARNO also blocked glucoseinduced activation of Cdc42 and Rac1 suggesting that ARNO/Arf6 might be upstream to Cdc42 and Rac1 activation steps, which are necessary for GSIS [10]. Our current observations further validate that model that silencing of nm23-H1 inhibits glucose-induced Arf6 activation. In this context, it has been reported previously by Palacios and associates that Arf6-GTP recruits nm23-H1 to facilitate dynamin-mediated endocytosis during adherens junction disassembly [33]. While this signaling step places Arf6 upstream to nm23-H1, it still is compatible with our findings since these studies have provided evidence to implicate $\mathrm{nm} 23-\mathrm{H} 1$ as a source for GTP, which is required for Arf6 activation. While such a potential possibility that GSIS involves nm23-H1 mediated translocation/recruitment of ARNO for Arf6 exists in the $\beta$-cells, it remains to be verified experimentally.

It is noteworthy that Otsuki and coworkers have demonstrated that nm23-H1 regulates Rac1 by interaction with Tiam1, which is a known GEF for Rac1 [34]. These investigators have demonstrated that over expression of WT nm23-H1, but not the kinase-deficient mutants of nm23-H1, significantly promoted the conversion of GDP-bound G-proteins (e.g., Cdc42, Rac1 and RhoA) to their GTP-bound (active) forms. Based on these and other observations, these authors concluded that $\mathrm{nm} 23-\mathrm{H} 1$ acts as a regulator for Rac1. It should be noted that recent investigations from our laboratory have identified Tiam 1 as a GEF for Rac1 in pancreatic $\beta$-cells, and pharmacological inhibition of Tiam1-Rac1 signaling pathway (NSC23766) markedly reduced GSIS, suggesting that Tiam1-Rac1 signaling pathway in important for GSIS [17]. In this context, our earlier findings that WT nm23-H1 potentiated GSIS in INS-1 832/13 cells [35] alongside current data that kinase-dead mutants of nm23H1 prevented membrane-association of Rac1 in glucose-stimulated INS-1 832/13 cells further validates the hypothesis that nm $23-\mathrm{H} 1$ lies upstream to Rac1 in pancreatic $\beta$-cells in the facilitation of GSIS.

Lastly, previous studies from our laboratory have reported significant defects in the expression and the activity of NDP kinase in islets derived from the Goto-Kakizaki rat (GK rat), an animal model for type 2 diabetes [36]. Along these lines, we also reported a marked reduction in the expression and the NDPK activity of nm $23-\mathrm{H} 1$ in pancreatic $\beta$-cells exposed to gluco-lipotoxic conditions [37]. These data raise an interesting possibility that attenuated GSIS in these models, may, in part, be due to defects in nm23-Arf6-Rac1 signaling steps. Additional studies are needed to further validate this working model. In conclusion, we present the first evidence to implicate novel regulatory roles for $\mathrm{nm} 23-\mathrm{H} 1$ in physiological insulin secretion, which may, inpart, be due to its ability to regulate the activation of small Gproteins (Arf6 and Rac1), which we and others have demonstrated critical for GSIS to occur $[1,9,10,16-19,21-24]$.

\section{Abbreviations}

ARF6 (ADP ribosylation factor6); ATP $\gamma$ S (Adenosine 5'-[ $\gamma$-thio] triphosphate); GDP (Guanosine diphosphate); G-proteins (Guanosine triphosphate-binding proteins); GSIS (Glucose-stimulated insulin secretion); GTP (Guanosine triphosphate); GTP $\gamma \mathrm{S}$ (Guanosine 5'-[ $\gamma$-thio] triphosphate); NDPK (Nucleoside diphosphate kinase); nm23-H1 (Tumor metastasis suppressor gene, which also represents the NDP kinase A isoform); and nm23H2 (Tumor metastasis suppressor gene, which also represents the NDP kinase B isoform). 
Veluthakal/Kaetzel/Kowluru: $\mathrm{nm} 23-\mathrm{H} 1$ in Insulin Secretion

\section{Acknowledgements}

This research was supported in part by a Merit Review award [to AK; 1BX000469] from the Department of Veterans Affairs, Office of Research and Development [Biomedical Laboratory Research and Development] and National Institutes of Health [DK074921 to AK and CA159871 to DK]. AK is the recipient of a Senior Research Career Scientist Award from the Department of VA. The authors thank Drs. Suresh V. Madathilparambil, Vasudeva Kamath and Bhavaani Jayaram for excellent technical assistance in these studies. We also thank Prof. Chris Newgard for kindly providing INS-1 832/13 cells used in the current investigation.

\section{References}

1 Kowluru A: Regulatory roles for small G proteins in the pancreatic beta-cell: lessons from models of impaired insulin secretion. Am J Physiol Endocrinol Metab 2003;285:669-684.

2 Newgard CB, McGarry JD: Metabolic coupling factors in pancreatic $\beta$ cell signal transduction. Ann Rev Biochem 1995;64:689-719.

3 Prentki M, Matschinsky FM: Calcium, cAMP, and phospholipid-derived messengers in coupling mechanisms of insulin secretion. Physiol Rev 1987;67:1223-1226.

4 Metz SA, Rabaglia ME, Pintar TJ: Selective inhibitors of GTP-synthesis impede exocytotic insulin release from intact rat islets. J Biol Chem 1992;66:12517-12527.

5 Metz SA, Meredith M, Rabaglia ME, Kowluru A: Small elevations of glucose concentration redirect and amplify the synthesis of guanosine 5'-triphosphate in rat islets. J Clin Invest 1993;92:872-882.

6 Kowluru A, Metz SA: GTP and its binding proteins in the regulation of insulin exocytosis; in Draznin B, LeRoith D (eds): Molecular Biology of Diabetes. Totowa, NJ: Humana, 1994, pp 249-283.

$7 \quad$ Kowluru A, Robertson RP, Metz SA: GTP-binding proteins in the regulation of pancreatic $\beta$ cell function; in LeRoith D, Taylor SI, Olefsky JM (eds): Diabetes Mellitus. A Fundamental and Clinical Text. Philadelphia, PA: Lippincott Williams \& Wilkins, 2000, pp 78-94.

8 Robertson RP, Seaquist ER, Walseth TF: G-proteins and modulation of insulin secretion. Diabetes 1991;40:1-6.

9 Kowluru A: Small G proteins in islet beta-cell function. Endocr Rev 2010;31:52-78.

10 Jayaram B, Syed I, Kyathanahalli CN, Rhodes CJ, Kowluru A: Arf nucleotide binding site opener [ARNO] promotes sequential activation of Arf6, Cdc42 and Rac1 and insulin secretion in INS 832/13 $\beta$-cells and rat islets. Biochem Pharmacol 2011;81:1016-1027.

11 Kimura N, Shimada N, Ishijima Y, Fukuda M, Takagi Y, Ishikawa N: Nucleoside diphosphate kinases in mammalian signal transduction systems: recent development and perspective. J Bioenerg Biomembr 2003;35:41-47.

12 Cuello F, Schulze RA, Heemeyer F, Meyer HE, Lutz S, Jakobs KH, Niroomand F, Wieland T: Activation of heterotrimeric G proteins by a high energy phosphate transfer via nucleoside diphosphate kinase (NDPK) $\mathrm{B}$ and Gbeta subunits. Complex formation of NDPK B with Gbeta gamma dimers and phosphorylation of His-266 IN Gbeta. J Biol Chem 2003;278:7220-7226.

13 Hippe HJ, Lutz S, Cuello F, Knorr K, Vogt A, Jakobs KH, Wieland T, Niroomand F: Activation of heterotrimeric G proteins by a high energy phosphate transfer via nucleoside diphosphate kinase (NDPK) B and Gbeta subunits. Specific activation of Gsalpha by an NDPK B. Gbetagamma complex in H10 cells. J Biol Chem 2003;278:72277233.

14 Kowluru A, Metz SA: Characterization of nucleoside diphosphokinase activity in human and rodent pancreatic beta cells: evidence for its role in the formation of guanosine triphosphate, a permissive factor for nutrient-induced insulin secretion. Biochemistry 1994;33:12495-12503.

15 Kepner EM, Yoder SM, Oh E, Kalwat MA, Wang Z, Quilliam LA, Thurmond DC: Cool-1/ßPIX functions as a guanine nucleotide exchange factor in the cycling of Cdc42 to regulate insulin secretion. Am J Physiol Endocrinol Metab 2011;301:1072-1080.

16 Wang Z, Thurmond DC: Mechanisms of biphasic insulin-granule exocytosis -roles of the cytoskeleton, small GTPases and SNARE proteins. J Cell Sci 2009;122:893-903. 


\section{Cellular Physiology Cell Physiol Biochem 2013;32:533-541 and Biochemistry \\ Veluthakal/Kaetzel/Kowluru: nm23-H1 in Insulin Secretion}

17 Veluthakal R, Madathilparambil SV, McDonald P, Olson LK, Kowluru A: Regulatory roles of Tiam1, a guanine nucleotide exchange factor for Rac1, in glucose-stimulated insulin secretion in pancreatic beta-cells. Biochem Pharmacol 2009;77:101-113.

18 Li J, Luo R, Kowluru A, Li G: Novel regulation by Rac1 of glucose-and forskolin-induced insulin secretion in INS-1 beta-cells. Am J Physiol Endocrinol Metab 2004;286:818-827.

19 Lawrence JT, Birnbaum MJ: ADP-ribosylation factor 6 regulates insulin secretion through plasma membrane phosphatidylinositol 4,5-bisphosphate. Proc Natl Acad Sci USA 2003;100:13320-13325.

20 Kowluru A, Tannous M, Chen HQ: Localization and characterization of the mitochondrial isoform of the nucleoside diphosphate kinase in the pancreatic beta cell: evidence for its complexation with mitochondrial succinyl-CoA synthetase. Arch Biochem Biophys 2002;398:160-169.

21 Daniel S, Noda M, Cerione RA, Sharp GW: A link between Cdc42 and syntaxin is involved in mastoparanstimulated insulin release. Biochemistry 2002;41:9663-9671.

22 Kowluru A, Seavey SE, Li G, Sorenson RL, Weinhaus AJ, Nesher R, Rabaglia ME, Vadakekalam J, Metz SA: Glucose-and GTP-dependent stimulation of the carboxyl methylation of CDC42 in rodent and human pancreatic islets and pure beta cells. Evidence for an essential role of GTP-binding proteins in nutrientinduced insulin secretion. J Clin Invest 1996;98:540-555.

23 Amin RH, Chen HQ Veluthakal R, Silver RB, Li J, Li G, Kowluru A: Mastoparan-induced insulin secretion from insulin-secreting betaTC3 and INS-1 cells: evidence for its regulation by Rho subfamily of G proteins. Endocrinology 2003;144:4508-4518.

24 Kowluru A, Veluthakal R: Rho guanosine diphosphate-dissociation inhibitor plays a negative modulatory role in glucose-stimulated insulin secretion. Diabetes 2005;54:3523-3529.

25 Agarwal RP, Robinson B, Parks RE: Nucleoside diphosphokinase from erythrocytes. Methods Enzymol 1978;51:376-386.

-26 Wagner PD, Vu ND: Phosphorylation of ATP-citrate lyase by nucleoside diphosphate kinase. J Biol Chem 1995;270:21758-21764.

27 Ma D, McCorkle JR, Kaetzel DM: The metastasis suppressor NM23-H1 possesses 3'-5' exonuclease activity. J Biol Chem 2004;279:18073-18084.

28 Zhang Q McCorkle JR, Novak M, Yang M, Kaetzel DM: Metastasis Suppressor Function of NM23-H1 Requires its 3'-5' Exonuclease Activity. Int J Cancer 2011;128:40-50.

29 de la Rosa A, Williams RL, Steeg PS: Nm23/nucleoside diphosphate kinase: toward a structural and biochemical understanding of its biological functions. Bioessays 1995;17:53-62.

- 30 Postel EH: NM23-NDP kinase. Int J Biochem Cell Biol 1998;12:1291-1295.

- 31 Choudhuri T, Murakami M, Kaul R, Sahu SK, Mohanty S, Verma SC, Kumar P, Robertson ES: Nm23-H1 can induce cell cycle arrest and apoptosis in B cells. Cancer Biol Ther 2010;9:1065-1078.

-32 Parks RE, Agarwal RP: Nucleoside diphosphokinases; in Boyer P. (ed): The Enzymes. Academic Press, New York, 1973, pp 303-333.

-33 Palacios F, Schweitzer JK, Boshans RL, D’Souza-Schorey C: ARF6-GTP recruits Nm23-H1 to facilitate dynamin-mediated endocytosis during adherens junctions disassembly. Nat Cell Biol 2002;4:929-936.

-34 Otsuki Y, Tanaka M, Yoshii S, Kawazoe N, Nakaya K Sugimura H: Tumor metastasis suppressor nm23H1 regulates Rac1 GTPase by interaction with Tiam1. Proc Natl Acad Sci USA 2001;98:4385-4390.

- 35 Kowluru A, Veluthakal R, Kaetzel DM: Regulatory roles for nm23/nucleoside diphosphate kinase-like enzymes in insulin secretion from the pancreatic islet beta cell. J Bioenerg Biomembr 2006;38:227-232.

-36 Metz SA, Meredith M, Vadakekalam J, Rabaglia ME, Kowluru A: A defect late in stimulus-secretion coupling impairs insulin secretion in Goto-Kakizaki diabetic rats. Diabetes 1999;48:1754-1762.

37 Veluthakal R, Suresh MV, Kowluru A: Down-regulation of expression and function of nucleoside diphosphate kinase in insulin-secreting beta-cells under in vitro conditions of glucolipotoxicity. Mol Cell Biochem 2009;329:121-129. 